\title{
Transcranial Color-Coded Duplex as A Predictor of Early Outcome in Acute Ischemic Stroke
}

\author{
K.S.Moselhy ${ }^{1}$, A.A.Murad ${ }^{1}$, S.I.El-Jaafary ${ }^{2}$ and M.A.Dawood ${ }^{1}$ \\ ${ }^{1}$ Neuropsychiatry Dept., Faculty of Medicine, Benha Univ., Benha, Egypt \\ ${ }^{2}$ Neurology Dept., Faculty of Medicine, Cairo Univ., Cairo, Egypt
}

E-Mail:Marwa.12@gmail.com

\begin{abstract}
The improvement of transcranial shading coded duplex sonography (TCCS) has restored the desire for protected, continuous bedside mind imaging past adolescence. This exploration gives a review of the job transcranial shading coded duplex (TCCD) as an indicator of early result in intense ischemic stroke. In this relative cross-sectional examination, we looked to research the capacity of TCCD to recognize early clinical result in patients with intense ischemic stroke. 50 CVIS patients were enlisted for this examination. Extracranial carotid course duplex and TCCD was done at day 1. Appraisal of seriousness of stroke was done dependent on NIHSS at introduction. Evaluation of result at 3 months after beginning was done dependent on Barthel record score (BI). Center cerebral course (MCA) stenosis and unevenness were essentially connected with helpless result. Stenosis was higher in dead cases. Be that as it may, typical MCA status was altogether connected with great result. Patients with consolidated MCA+ intracranial carotid supply route (ICA) stenosis had essentially higher NIHSS at introduction, fundamentally lower BI than isolated intracranial MCA stenosis. The presence of intracranial MCA stenosis or lopsidedness is an autonomous indicator of helpless result for stroked patients.
\end{abstract}

Keywords: Transcranial color-coded duplex, Middle cerebral artery, Acute cerebrovascular ischemic stroke.

\section{Introduction}

Stroke is characterized by the World Health Organization as a clinical condition comprising of 'quickly creating clinical indications of central (here and there worldwide) aggravation of cerebral capacity, enduring over 24 hours or prompting passing with no evident reason other than that of vascular origin' [1].

Anticipating the clinical course of patients with intense stroke keeps on being a prognostic test for stroke doctors. Early danger delineation of intense stroke patients has contributed significant clinical assessments of mortality hazard utilizing dependable and basic prognostic models [2].

Appraisal of the cerebral vasculature can be performed by utilizing transcranial Doppler (TCD) ultrasound, the lone non-obtrusive assessment that gives a dependable assessment of intracranial blood stream designs continuously, adding physiological data to the anatomical data acquired from other neuroimaging modalities. TCD is moderately modest, can be performed bedside, and permits observing both in intense crisis settings just as for delayed periods with a high fleeting goal making it ideal for contemplating dynamic cerebrovascular responses [3].

In intense cerebral ischemia, TCD can give quick data about the hemodynamic status of the cerebral course, checking recanalization continuously with a potential for improving tissue plasminogen activator (TPA) incited thrombolysis. Progressed utilizations of TCD make it a significant and important device for assessing stroke instruments, plan and screen treatment and decide prognosis [3].

TCD has a set up clinical incentive in the demonstrative workup of stroke patients and is recommended as basic parts of an exhaustive stroke center.3 It offers noninvasive data on stream speed, cerebral $\mathrm{CO} 2$ reactivity, and the presence of miniature embolic signs. These three boundaries may give new indicators of expanded danger of stroke repeat and other vascular difficulties. Transcranial Doppler ultrasonography permits the noninvasive examination of blood vessel blood stream inside the skull [4].

\section{Patients and methods}

This is A comparative cross-sectional study, conducted in Benha University Hospital from June 2017 and it continued until the required sample size was completed. Study subjects were informed of the possibility of using the data obtained for academic purpose. Confidentiality was assured to all participants and data used for this study were stripped of personally identifiable information.

\subsection{Patients}

Participants were chosen by non-random technique, all patients with first acute ischemic stroke fulfilling the inclusion criteria and agree to participate were included in the study. Included were patients with acute cerebral ischemia in the MCA (middle cerebral artery) territory with a neurological deficit lasting more than 24 hours, and patent temporal window. Excluded were patients with history of previous ischemic stroke, cerebral hemorrhage on CT, preexisting neurological, psychiatric, or other illnesses that would confound the neurological evaluations, severe concomitant medical condition (e.g., metastatic cancer, AIDS, renal failure, liver failure...etc.), pregnancy, and no temporal bone window.

\subsection{Methods}

All patients were subjected to the following: Thorough medical history taking, full general and neurological examination, ECG, Blood sugar level. Serum electrolytes level, Liver function test, Kidney function test and Lipid profile. 
Patients' initial stroke severity was assessed by National Institutes of Health Stroke Scale, or NIH Stroke Scale (NIHSS)5 on admission. Patients' stroke outcome was assessed 3 months after onset of stroke by: The Barthel ADL (activity of daily living) Index [6].

Cranial Computed Tomography (CT) was done to confirm diagnosis of ischemic stroke and exclusion of hemorrhage. It was done initially at presentation; findings were classified into: No lesion and early ischemic signs. It was repeated after 48 hours. CT findings were classified according to size to lacunar stroke and large stroke.

Transcranial color duplex sonography (TCCD) was performed for each patient within 24 hours of the onset of symptoms, findings were classified 7 into: \%. Normal MCA when side-to-side flow velocity difference is less than $30 \%$. MCA asymmetry, when the side-to-side flow velocity difference is more than 30 . MCA stenosis, MCA and other intracranial arteries stenosis were tabulated according to Baumgartner et al. [8] Table (1).

Table (1) Criteria for intracranial artery stenosis [8].

\begin{tabular}{|c|c|c|}
\hline \multicolumn{3}{|c|}{ Peak systolic flow velocity $(\mathrm{cm} / \mathrm{second})$} \\
\hline & $<\% 0^{\circ}$ & $\geq \% 0^{0}$. \\
\hline Anterior cerebral artery & $\geq 100$ & $\geq Y r$. \\
\hline Middle cerebral artery & $\geq 1 Y$. & $\geq 100$ \\
\hline Posterior cerebral artery & $\geq 1 \ldots$ & $\geq 1 \leqslant 0$ \\
\hline Vertebral artery & $\geq 1 \ldots$ & $\geq 1 \leqslant 0$ \\
\hline Basilar artery & $\geq 9$ & $\geq 1 r$. \\
\hline
\end{tabular}

Extracranial Carotid Duplex was done to all patients. The intima - media complex thickness was measured at the far wall. Carotid arteries were considered normal if the intima- media thickness is $<1.0 \mathrm{~mm}$, no plaque detected and peak systolic velocity at the proximal ICA (PSVICA) is less than $125 \mathrm{~cm} / \mathrm{s}$. Carotid atherosclerotic disease was considered present if the intima-media complex showed diffuse thickening $(\geq 1.0 \mathrm{~mm})$ or if

Table (2) Doppler criteria for diagnosis of ICA stenosis [9]. carotid plaques were detected ${ }^{9}$. Pulsed Doppler signals were routinely recorded from the CCA just proximal to the bifurcation, the origin of the external carotid artery, proximal, mid and if accessible distal ICA. They were recorded in the longitudinal view with less than $60^{\circ}$ insonation angle.

Results were classified according to Table (2) [9].

\begin{tabular}{lccc}
\hline $\begin{array}{l}\text { Diameter } \\
\text { stenosis }(\%)\end{array}$ & PSV $(\mathbf{c m} / \mathbf{s e c})$ & EDV $(\mathbf{c m} / \mathbf{s e c})$ & Ica/CCA PSV ratio \\
\hline Normal & $<125$ & $<40$ & $<2.0$ \\
$<\mathbf{5 0}$ & $<125$ & $<40$ & $<2.0$ \\
$\mathbf{5 0 - 6 9}$ & $125-230$ & $40-100$ & $2.0-4.0$ \\
$\geq \mathbf{7 0}$ & $>230$ & $>100$ & $>4.0$ \\
Near total & Variable & Variable & Variable \\
Occlusion & undetectable & undetectable & Not applicable \\
Total occlusion & & \\
\hline
\end{tabular}

CCA: common carotid artery; ICA: internal carotid artery; EDV: end-diastolic velocity; PSV: peak systolic velocity.

\subsection{Statistical analysis}

The collected data was revised, coded, and tabulated using Statistical package for Social Science (IBM Corp. Released 2011. IBM SPSS Statistics for Windows, Version 20.0. Armonk, NY: IBM Corp.). Data were presented and suitable analysis was done according to the type of data obtained for each parameter. ShapiroWilk test was done to test the normality of data distribution. Categorical data were presented as number and percentages while quantitative data were expressed as mean \pm standard deviation and range. Chi square test (X2), or Fisher's exact test (FET), were used to analyze categorical variables. Student T Test was used to assess the statistical significance of the difference between two study group means. For the comparison of more than two groups' means, one-way analysis of variance (ANOVA) was used. Mann Whitney Test (U test) was used to assess the statistical significance of the difference of a nonparametric variable between two study groups. Logistic and ordinal regression analyses were used for prediction of risk factors, using generalized linear models. The accepted level of significance in this work was stated at 0.05 ( $\mathrm{P}<0.05$ was considered significant).

\section{Results}

The present study was conducted on 50 cases. Their mean age was 67.2 years. They were 34 males $(68 \%)$ and 16 females $(32 \%)$. All studied cases were assessed thoroughly, seeking for risk factors, $60 \%$ were smokers, $52 \%$ had DM, $74 \%$ had hypertension, $30 \%$ had IHD, $28 \%$ had AF, $6 \%$ had other cardiopathies, and $38 \%$ had previous TIA. $58 \%$ of cases have high cholesterol level and $62 \%$ of them have high triglycerides level. 
Initial CT revealed $18 \%$ had early ischemic signs, and $82 \%$ were free. At follow up, CT revealed $26 \%$ lacunar, and $74 \%$ larger stroke in CT. Median stroke size was $19.5 \mathrm{~mm}$, and ranged from 1 to $150 \mathrm{~mm}$.

MCA was evaluated by intracranial duplex at presentation, $74 \%$ were free, $14 \%$ were asymmetric and
12 were stenosed. Left ACA was affected in 2 cases, left MCA was affected in 3 cases, right ACA and MCA were affected in 1 case, right MCA was affected in 8 cases, right MCA and left ACA was affected in 1 case Table (3)

Table (3) MCA state at presentation in all studied cases.

\begin{tabular}{lccc}
\hline MCA state & & \multicolumn{2}{c}{$\begin{array}{c}\text { Cases } \\
\mathbf{N = 5 0}\end{array}$} \\
\cline { 3 - 4 } & & $\mathbf{N}$ & $\mathbf{\%}$ \\
\hline Initial MCA state & Normal & 37 & $74 \%$ \\
& Asymmetry & 7 & $14 \%$ \\
\multirow{5}{*}{ Site } & Stenosis & 6 & $12 \%$ \\
& Normal & 35 & $70 \%$ \\
& Left ACA & 2 & $4 \%$ \\
& Left MCA & 3 & $6 \%$ \\
& Right ACA, Right MCA & 1 & $2 \%$ \\
& Right MCA & 8 & $16 \%$ \\
& Right MCA, Left ACA & 1 & $2 \%$ \\
\hline
\end{tabular}

Regarding right ICA, median PSV was 60.5, ranged from 32 to $130 \mathrm{~cm} / \mathrm{sec}$; median IMT was 0.7 , ranged from 0.2 to $1.7 \mathrm{~cm}$. Regarding left ICA, median PSV was 61 , ranged from 33 to $270 \mathrm{~cm} / \mathrm{sec}$; median IMT was 0.8 ,

Table (4) Extracranial duplex findings. ranged from 0.3 to $1.9 \mathrm{~cm}$. ICA stenosis accounted for 10 cases $(20 \%)$, out of them $40 \%$ at the left side and $60 \%$ at the right side. Median degree of stenosis was 55, ranged from 50 to $80 \%$. Plaques were found in $36 \%$ of all studied cases Table (4).

\begin{tabular}{lcccc}
\hline & & & \multicolumn{2}{c}{ Cases } \\
N=50
\end{tabular}

Initial NIHSS increased significantly with decreased BI score, up to the highest level in death Table (5).

Table (5) Association of stroke outcome (assessed by BI score) with NIHSS.

\begin{tabular}{lcccccc}
\hline & $\begin{array}{c}\text { Slightly dependent } \\
\mathbf{N = 6}\end{array}$ & $\begin{array}{c}\text { Moderately } \\
\text { dependent } \\
\mathbf{N = 9}\end{array}$ & $\begin{array}{c}\text { Severely dependent } \\
\mathbf{N = 3 0}\end{array}$ & $\begin{array}{c}\text { Died } \\
\mathbf{N = 5}\end{array}$ & P1 & Post hoc \\
\cline { 2 - 5 } & $\begin{array}{c}\text { Median } \\
\text { min-max }\end{array}$ & $\begin{array}{c}\text { Median } \\
\text { min-max }\end{array}$ & $\begin{array}{c}\text { Median } \\
\text { min-max }\end{array}$ & $\begin{array}{c}\text { Median } \\
\text { min- } \\
\text { max }\end{array}$ & \\
\hline Initial & 4 & 9 & 24 & 36 & $<0.001$ & P2=0.366 \\
NIHSS & $3-6$ & $5-15$ & $16-38$ & $31-39$ & $P 3<0.001$ \\
& & & & & & P4=0.024 \\
\hline
\end{tabular}


Early ischemic signs in initial CT increased significantly with worse BI outcome. Stroke size did not differ significantly in disabled patients but was significantly associated with death. Decreased frequency of lacunar lesions was associated with worsened BI score Table (6).

Table (6) Association of stroke outcome (assessed by BI score) with CT findings.

\begin{tabular}{|c|c|c|c|c|c|c|c|c|}
\hline & & & $\begin{array}{c}\text { Slightly } \\
\text { dependent } \\
\mathrm{N}=6\end{array}$ & $\begin{array}{c}\text { Moderately } \\
\text { dependent } \\
\text { N=9 }\end{array}$ & $\begin{array}{c}\text { Severely } \\
\text { dependent } \\
\mathbf{N}=\mathbf{3 0}\end{array}$ & $\begin{array}{l}\text { Died } \\
N=5\end{array}$ & P1 & Post hoc \\
\hline \multirow{3}{*}{$\begin{array}{l}\text { Initial } \\
\text { CT }\end{array}$} & no lesion & $\mathrm{N}$ & 6 & 9 & 24 & 2 & \multirow[b]{3}{*}{0.038} & \multirow{3}{*}{$\begin{array}{l}\mathrm{P} 3=0.305 \\
\mathrm{P} 3=0.095\end{array}$} \\
\hline & & $\%$ & $100 \%$ & $100 \%$ & $80 \%$ & $40 \%$ & & \\
\hline & $\begin{array}{l}\text { Early } \\
\text { Ischemic } \\
\text { signs }\end{array}$ & $\begin{array}{l}\mathrm{N} \\
\%\end{array}$ & $\begin{array}{c}0 \\
0 \%\end{array}$ & $\begin{array}{c}0 \\
0 \%\end{array}$ & $\begin{array}{c}6 \\
20 \%\end{array}$ & $\begin{array}{c}3 \\
60 \%\end{array}$ & & \\
\hline \multirow[t]{2}{*}{$\begin{array}{l}\text { Follow } \\
\text { up CT }\end{array}$} & Stroke size & $\begin{array}{l}\text { Median } \\
\text { min- } \\
\max \end{array}$ & $\begin{array}{c}30 \\
30-30\end{array}$ & $\begin{array}{c}3.3 \\
1-18\end{array}$ & $\begin{array}{c}18 \\
2-150\end{array}$ & $\begin{array}{l}137 \\
20- \\
145\end{array}$ & 0.017 & \multirow{2}{*}{$\begin{array}{l}\mathrm{P} 2=0.135 \\
\mathrm{P} 3=0.061 \\
\mathrm{P} 4=0.024 \\
\mathrm{P} 2=0.667 \\
\mathrm{P} 3=0.018 \\
\mathrm{P} 4=0.386\end{array}$} \\
\hline & Lacunar & $\begin{array}{l}\mathrm{N} \\
\%\end{array}$ & $\begin{array}{c}4 \\
66.7 \%\end{array}$ & $\begin{array}{c}5 \\
55.6 \%\end{array}$ & $\begin{array}{c}4 \\
13.3 \%\end{array}$ & $\begin{array}{c}0 \\
0 \%\end{array}$ & 0.003 & \\
\hline
\end{tabular}

Higher MCA and ACA abnormal duplex findings were significantly associated with worse outcome (less BI index score) Table (7). Significant association was found between stroke outcome (assessed by BI score) and MCA status. Presence of MCA asymmetry and stenosis was significantly associated with low BI score and stenosis was higher in dead cases Table (8).
Higher frequency of extracranial ICA stenosis was significantly associated with severely dependent and dead cases. No significant association was found between BI score and ICA stenosis site and degree. And plaque frequency increased in severely dependent cases (with low BI score).

Table (7) Association of stroke outcome (assessed by BI score) with intracranial duplex findings.

\begin{tabular}{|c|c|c|c|c|c|c|c|}
\hline & & & $\begin{array}{c}\text { Slightly } \\
\text { dependent } \\
\mathrm{N}=6\end{array}$ & $\begin{array}{l}\text { Moderately dependent } \\
\qquad \mathrm{N}=9\end{array}$ & $\begin{array}{l}\text { Severely dependent } \\
\qquad \mathbf{N}=\mathbf{3 0}\end{array}$ & $\begin{array}{l}\text { Died } \\
N=5\end{array}$ & $\mathbf{P}$ \\
\hline & & & $\begin{array}{c}\text { Median } \\
\text { min-max }\end{array}$ & $\begin{array}{l}\text { Median } \\
\text { min-max }\end{array}$ & $\begin{array}{l}\text { Median } \\
\text { min-max }\end{array}$ & $\begin{array}{c}\text { Median } \\
\text { min-max }\end{array}$ & \\
\hline \multirow[t]{6}{*}{$\begin{array}{l}\text { At } \\
\text { presentation }\end{array}$} & \multirow[t]{3}{*}{ Right } & $\mathrm{MCA}$ & $\begin{array}{c}60 \\
54-84\end{array}$ & $\begin{array}{c}55 \\
54-74\end{array}$ & $\begin{array}{c}82.5 \\
53-163\end{array}$ & $\begin{array}{c}109 \\
55-164\end{array}$ & $0.047 *$ \\
\hline & & ACA & $\begin{array}{c}42 \\
35-42\end{array}$ & $\begin{array}{c}47 \\
37-65\end{array}$ & $\begin{array}{c}52 \\
30-79\end{array}$ & $\begin{array}{c}78 \\
35-113\end{array}$ & $0.012 *$ \\
\hline & & ICA & $\begin{array}{c}39 \\
30-49\end{array}$ & $\begin{array}{c}41 \\
29-49\end{array}$ & $\begin{array}{c}45 \\
37-52\end{array}$ & $\begin{array}{c}47 \\
37-49\end{array}$ & 0.248 \\
\hline & \multirow[t]{3}{*}{ Left } & MCA & $\begin{array}{c}61 \\
43-85\end{array}$ & $\begin{array}{c}63 \\
37-85\end{array}$ & $\begin{array}{c}79.5 \\
36-161\end{array}$ & $\begin{array}{c}81 \\
38-158\end{array}$ & $0.034 *$ \\
\hline & & $\mathrm{ACA}$ & $\begin{array}{c}45 \\
44-50\end{array}$ & $\begin{array}{c}46 \\
40-60\end{array}$ & $\begin{array}{c}49 \\
38-95\end{array}$ & $\begin{array}{c}50 \\
45-89\end{array}$ & $0.042 *$ \\
\hline & & ICA & $\begin{array}{c}35 \\
30-62\end{array}$ & $\begin{array}{c}43 \\
37-61\end{array}$ & $\begin{array}{c}48.5 \\
26-161\end{array}$ & $\begin{array}{c}50 \\
26-61\end{array}$ & 0.130 \\
\hline
\end{tabular}

Table (8) Association of stroke outcome (assessed by BI score) with MCA state.

\begin{tabular}{|c|c|c|c|c|c|c|}
\hline & & $\begin{array}{c}\text { Slightly } \\
\text { dependent } \\
\mathrm{N}=6\end{array}$ & $\begin{array}{c}\text { Moderately } \\
\text { dependent } \\
\text { N=9 }\end{array}$ & $\begin{array}{c}\text { Severely } \\
\text { dependent } \\
\text { N=30 }\end{array}$ & $\begin{array}{l}\text { Died } \\
N=5\end{array}$ & $\mathbf{P}$ \\
\hline & & $\mathbf{N}$ & $\mathbf{N}$ & $\mathbf{N}$ & $\mathbf{N}$ & \\
\hline & & $\%$ & $\%$ & $\%$ & $\%$ & \\
\hline \multirow{6}{*}{$\begin{array}{l}\text { MCA } \\
\text { state }\end{array}$} & \multirow[t]{2}{*}{ Normal } & 6 & 9 & 20 & 2 & \multirow{2}{*}{$0.028 *$} \\
\hline & & $100 \%$ & $100 \%$ & $66.7 \%$ & $40 \%$ & \\
\hline & \multirow[t]{2}{*}{ Asymmetry } & 0 & 0 & 6 & 1 & \multirow{2}{*}{$0.049 *$} \\
\hline & & $0 \%$ & $0 \%$ & $20 \%$ & $20 \%$ & \\
\hline & \multirow[t]{2}{*}{ Stenosis } & 0 & 0 & 4 & 2 & \multirow{2}{*}{$0.012 *$} \\
\hline & & $0 \%$ & $0 \%$ & $13.3 \%$ & $40 \%$ & \\
\hline
\end{tabular}

Poor outcome was significantly associated with higher ICA IMT ( $\mathrm{p}=0.033)$, and ICA PSV ( $\mathrm{p}=0.007)$.
Poor outcome was significantly associated with IC stenosis $(\mathrm{p}<0.001)$. Site and degree of stenosis were not 
associated with outcome after 3 months. Poor outcome was significantly associated with plaque formation $(\mathrm{p}<0.001)$.
Patients with combined MCA+ICA stenosis have significantly higher NIHSS at presentation, significantly lower BI than separate Table (9).

Table (9) Association of combined MCA and ICA stenosis with outcome.

\begin{tabular}{|c|c|c|c|c|c|c|}
\hline \multirow{3}{*}{ NIHSS at presentation } & \multirow[b]{3}{*}{$\begin{array}{c}\text { Median, } \\
\text { range }\end{array}$} & \multicolumn{4}{|c|}{ Combined MCA+ICA stenosis } & \multirow{3}{*}{$\begin{array}{c}\mathbf{P} \\
0.020 *\end{array}$} \\
\hline & & \multicolumn{2}{|c|}{$\begin{array}{c}\text { Separate } \\
\mathbf{N}=4\end{array}$} & \multicolumn{2}{|c|}{$\begin{array}{c}\begin{array}{c}\text { Combined } \\
\mathrm{N}=15\end{array} \\
\end{array}$} & \\
\hline & & 27.5 & $26-39$ & 33 & $20-39$ & \\
\hline BI & $\begin{array}{c}\text { Median, } \\
\text { range }\end{array}$ & 50 & $25-55$ & 25 & $0-50$ & $0.016^{*}$ \\
\hline
\end{tabular}

Ordinal regression analysis was conducted for prediction of poor outcome by BI score, using age, gender, smoking, DM, hypertension, IHD, AF, cardiopathy, TIA, TC, TG, basal NIHSS, CT, TCCD findings as covariates. Older age, hypertension, previous TIA, higher TC, TG, basal NIHSS, abnormal CT, TCCD were associated with susceptibility to poor outcome (assessed by BI score) in univariable analysis. However, considering significant covariates in univariable analysis into multivariable analysis revealed that only hypertension, higher TC, abnormal TCCD were suggested to be predictors of poor outcome for stroked patients Table (10).

Table (10) Regression analysis for prediction of poor outcome (assessed by BI score).

\begin{tabular}{|c|c|c|c|c|c|c|c|c|}
\hline \multirow[b]{3}{*}{ Age } & \multicolumn{4}{|c|}{ Univariable } & \multicolumn{4}{|c|}{ Multivariable } \\
\hline & \multirow{2}{*}{$\frac{\mathbf{p}}{0.025^{*}}$} & \multirow{2}{*}{$\begin{array}{c}\text { OR } \\
1.015\end{array}$} & \multicolumn{2}{|c|}{$95 \% \mathrm{CI}$} & \multirow{2}{*}{$\begin{array}{c}\mathbf{p} \\
0.409\end{array}$} & \multirow{2}{*}{$\begin{array}{c}\mathbf{O R} \\
0.996\end{array}$} & \multicolumn{2}{|c|}{$95 \% \mathrm{CI}$} \\
\hline & & & 1.002 & 1.028 & & & 0.986 & 1.006 \\
\hline Gender & 0.969 & 1.004 & 0.815 & 1.238 & & & & \\
\hline Smoking & 0.622 & 1.051 & 0.862 & 1.282 & & & & \\
\hline DM & 0.484 & 1.072 & 0.883 & 1.302 & & & & \\
\hline Hypertension & $<0.001 * * *$ & 1.610 & 1.339 & 1.936 & $0.007 * *$ & 1.296 & 1.075 & 1.561 \\
\hline IHD & 0.365 & 1.103 & 0.893 & 1.362 & & & & \\
\hline $\mathbf{A F}$ & 0.414 & 1.094 & 0.882 & 1.358 & & & & \\
\hline Other cardiopathy & 0.980 & 0.995 & 0.660 & 1.500 & & & & \\
\hline Previous TIA & $0.025^{*}$ & 1.245 & 1.028 & 1.509 & 0.300 & 1.086 & 0.929 & 1.271 \\
\hline Total cholesterol & $<0.001 * * *$ & 1.003 & 1.002 & 1.004 & $0.044^{*}$ & 1.645 & 1.298 & 1.914 \\
\hline Triglycerides & $<0.001 * * *$ & 1.003 & 1.002 & 1.004 & 0.111 & 1.002 & 0.999 & 1.005 \\
\hline Basal NIHSS & $<0.001 * * *$ & 1.030 & 1.024 & 1.036 & 0.076 & 1.428 & 0.818 & 1.037 \\
\hline Abnormal initial CT & $0.027 *$ & 1.314 & 1.031 & 1.674 & 0.369 & 0.920 & 0.767 & 1.104 \\
\hline Abnormal TCCD & $0.003 * *$ & 1.345 & 1.105 & 1.637 & $0.005 * *$ & 1.002 & 1.001 & 1.004 \\
\hline
\end{tabular}

\section{Discussion}

Stroke is turning into a significant reason for sudden passing and incapacity in low-pay and center pay countries [10]. Over $65 \%$ of stroke survivors likewise endure an incapacity that blocks their capacity to complete every day living exercises unassisted3.

TCD boundaries have been utilized to analyze and foresee intracranial vascular illness, in light of the fact that the significant corridors inside the mind can be noninvasively and powerfully checked by methods for transcranial Doppler sonography. With TCD sonography, stream speeds in the huge supply routes in the cerebrum can be handily surveyed through the transient bone window3.

In our examination, one encountered agent did all the TCD enlistments. This avoids interobserver changeability.

Early ischemic signs in starting CT were characterized by the presence of at least one of the accompanying discoveries: (1) hyperdense MCA/basilar course sign; (2) sulcal destruction; (3) basal ganglia/subcortical hypodensity; and (4) loss of cortical dim white differentiation [11].

In the current investigation, early ischemic signs in starting CT were related fundamentally with helpless result (low BI list score, and high pace of mortality).

This outcome concurred with Six,12 who expressed that poor utilitarian result of stroke patients might be anticipated by early signs on CT and MRI.

Early CT signs have been discovered alone or in mix to be available in up to $92 \%$ of cases. It is additionally discovered that early changes were regularly connected with helpless result particularly if growing was present [13].

Conversely, Gao et al., [14] expressed that the prognostic estimation of NCCT for intense dead tissue might be low on the grounds that the presence of hypo- 
constriction is time-subordinate. They have indicated that past the initial 3 hours of stroke beginning, the hypoconstriction sign on NCCT is probably going to speak to the time-subordinate tissue pathophysiology of ischemia instead of infection seriousness.

This finding is upheld by creature models which have distinguished that when remaining cerebral blood stream is under $13 \mathrm{~mL} / 100 \mathrm{~g} / \mathrm{min}$ adenosine triphosphate (ATP) consumption can be seen inside 30 minutes [15].

In the current investigation, stroke size didn't vary essentially in handicapped patients yet was altogether connected with death. Bigger stroke size was essentially connected with higher mortality in subsequent CT. In any case, lacunar sores were related with acceptable result and was not related with higher mortality.

Demise in the principal months after stroke is chiefly clarified by huge infarct volumes, though sores of explicit supratentorial structures, generally in the left side of the equator, additionally add to poor useful outcomes [16].

Numerous reasons can clarify why bigger infarcts cause poor useful results. Other than the way that enormous injuries influence numerous diverse mind zones with explicit capacities, a few outcomes of stroke may result from the association of anatomical structures incorporated into complex utilitarian organizations, and this may happen all the more frequently in huge strokes [17].

It is conceivable that the cerebrum districts embroiled in the neurological shortfalls after intense mind injury are more noteworthy than what the consequences of sore manifestation planning examines recommend, in light of the fact that harm to zones engaged with pertinent useful organizations may bring about additional neurological deficits [18].

NIHSS has been utilized as an underlying stroke seriousness appraisal for an assortment of purposes including forecast of movement of intense stroke and patient outcomes [19].

High NIHSS at first was essentially connected with helpless result at 3 months, it was related with low BI score. It was likewise altogether connected with higher death rate.

These discoveries are in accordance with going before research, which announced that this factor could anticipate the 3-month utilitarian visualization in patients with intense ischemic stroke [20].

Han and Nam21 exhibited that higher NIHSS score at confirmation was freely connected with poor practical result.

Bhaskar et al. [3] found that the underlying stroke seriousness indicated the most grounded autonomous relationship to the danger of death and ominous result inside 90 days. Their discoveries additionally recommended that stroke seriousness is a free indicator of by and large utilitarian result.

In an investigation planned to assess the prognostic estimation of starting neurological status and change after $24 \mathrm{~h}$ as dictated by the NIHSS to foresee general utilitarian result at 90 days. NIHSS was a decent indicator of general useful result in the general accomplice of stroke patients [22].

Our outcomes demonstrate that it is critical to gauge stroke seriousness and make a change for stroke seriousness when revealing for both utilitarian result and death rates.

TCD ultrasonography essentially mirrors the hemodynamic data of the proximal MCA, inferable from limited insonation, and in this way unusually expanded or diminished speed mirrors a pathophysiologic condition in huge veins, for example, the proximal MCA [21].

Numerous investigations detailed that an expanded pulsatility list (PI) was related with psychological weakness and a bigger infarct volume in patients with ischemic stroke [23,24].

In this examination, higher MCA and ACA strange duplex discoveries were fundamentally connected with helpless result (low BI record score, and high pace of mortality).

MCA stenosis and deviation were essentially connected with helpless result. Stenosis was higher in dead cases. Be that as it may, typical MCA status was altogether connected with great result.

This outcome concurred with Aoki et al.25 who found that higher MCA PI was related with a helpless momentary result.

Han and Nam [21] found that a higher MCA unevenness file was altogether connected with poor useful result and announced that the MCA imbalance list estimated during the intense period of stroke can autonomously anticipate the 3 -months guess.

In an examination that checked sequential MCA PI with TCD during the initial 10 days after stroke beginning, an expansion in MCA PI was seen up to 3-5 days after beginning and MCA PI anticipated helpless result in patients with enormous MCA infarctions [26].

A few investigations revealed that MCA stream unevenness was a marker of basic carotid sickness and stroke, and proposed that it very well may be utilized as an option in contrast to perfusion-dissemination jumble in anticipating the presence of salvageable mind tissue in patients with intense ischemic stroke [27].

Notwithstanding the MCA imbalance, Baracchini et al. [28] announced that MCA no-stream estimated in the intense period of ischemic stroke was a free indicator of poor long haul result sorted by the Barthel list score.

Jeng et al. [29] additionally shows that patients with MCA stenosis gave higher NIHSS, which reflects more serious neurological deficiency at stroke beginning, were bound to show stroke-in-advancement and to have ominous result and higher mortality at 3 months after stroke when contrasted with patients without MCA stenosis.

The Warfarin-Aspirin Symptomatic Intracranial Disease (WASID) study indicated that the yearly repeat paces of stroke or TIA with suggestive intracranial atherosclerosis were almost $20 \%$, and most ensuing strokes were in a similar domain and non-lacunar [30]. 
In Allendoerfer et al. [31] preliminary, an unmistakable connection between vessel pathology and utilitarian result was noticed. An ordinary MCA finding was prescient of a decent practical result in $71 \%$ of subjects. Of the 57 patients with principle stem impediment, $50(88 \%)$ were dead or ward 3 months after stroke, and an impediment of the primary stem of the MCA inside $6 \mathrm{~h}$ after stroke was discovered to be an autonomous indicator of a helpless result.

Another examination in 2008 showed that patent MCA versus MCA branch or primary stem impediment analyzed on emergency clinic confirmation was related with a fundamentally higher possibility for clinical improvement inside 4 days after indication beginning in associates not treated with thrombolysis [32].

Patients with a MCA impediment contrasted and at first patent MCA had an altogether higher opportunity to be practically reliant following 3 months. This danger was lower for MCA branch impediments than for MCA mainstem occlusions [32].

Since indicative MCA stenosis predicts more regrettable result, more fast and thorough preventive measures would appear to be justified for these stroke patients. A new report recommends that more exacting intercessions should be justified in patients with suggestive intracranial corridor stenosis [33].

In our exploration, extracranial ICA stenosis, high IMT, and plaque development, was essentially connected with helpless result (low BI score, and high recurrence of death). Site and level of stenosis indicated no relationship with death rate. Furthermore, level of intracranial injuries going with extracranial ICA stenosis was $30 \%$.

It is accepted that more serious level of ICA stenosis all the more as often as possible is joined by intracranial stenosis or impediment. It might result from general and extreme atherosclerotic cycle and may show that carotid supply routes can fill in as a finder of cutting edge atherosclerosis. Serious level of stenosis and attendant neurological side effects should slant a vascular specialist to scan intracranial sores as a potential purpose behind cerebral incidents [34].

In this examination, patients with consolidated MCA+ICA stenosis had altogether higher NIHSS at introduction, essentially lower BI than independent intracranial MCA stenosis.

This outcome concurred with Jeng et al., 2017 [29] who announced that inside the MCA stenosis patients, those with superimposed extracranial ICA stenosis had considerably higher NIHSS on affirmation, more regrettable result, and higher mortality than those without ICA stenosis.

In an endurance investigation, the endpoint of consolidated stroke repeat or passing was fundamentally expanded in patients with both MCA and expanded further among those with both MCA and ICA stenosis [34].

An extensive extent of patients have a negative result, regardless of typical MCA discoveries in the sonographic assessment inside $6 \mathrm{~h}$ of stroke beginning, and comparative rates have been accounted for from contemplates using advanced deduction angiography [35].

\section{Conclusion and recommendation}

The present results revealed that: The presence of intracranial MCA stenosis or asymmetry is an independent predictor of poor outcome for stroked patients. Other independent predictors for poor outcome in this study are hypertension and high total cholesterol level.

Considering all the limitations of the study and the previous studies, we recommend that All patients with CVIS should be routinely examined by duplex ultrasound for intracranial and extracranial stenosis. Patients with intracranial stenosis on TCCD examination on admission should be closely monitored for CVIS associated complications. TCCD investigation could be of value in identifying subjects who are at risk of being severely dependent and liable for recurrent ischemic stroke within 3 months and judiciously selecting suitable treatment strategy to improve their outcome. Individuals with risk factors of stroke such as hypertension, high cholesterol levels should be monitored for extracranial and intracranial vascular pathology. In support of our current findings, further studies are necessary to confirm these results with a larger group of patients from many different areas/regions.

\section{References}

[1] N.Losseff, M.Brown, J.Grieve. Stroke and Cerebrovascular Diseases. Neurology: A Queen Square Textbook, Vol.4, PP.109-18,2009.

[2] S.Bhaskar, P.Stanwell, A.Bivard. The influence of initial stroke severity on mortality, overall functional outcome and in-hospital placement at 90 days following acute ischemic stroke: A tertiary hospital stroke register study. Neurol India, Vol. 65, PP. XXXX,2017.

[3] S.Bhaskar, P.Stanwell, A.Bivard. The influence of initial stroke severity on mortality, overall functional outcome and in-hospital placement at 90 days following acute ischemic stroke: A tertiary hospital stroke register study. Neurol India, Vol. 65, PP.XXXX,2017.

[4] R.Aaslid, T.M.Markwalder, H.Nornes. Noninvasive transcranial Doppler ultrasound recording of flow velocity in basal cerebral arteries. J Neurosurg, Vol.57, PP.769-74,1982.

[5] V. Hage. "The NIH stroke scale: a window into neurological status". Nursing Spectrum, Vol. 24 (15), PP. 44-49,2011.

[6] S.C.Loewen, B.A.Anderson. Predictors of stroke outcome using objective measurement scales. Stroke;, Vol. 21, PP.78-81,1990.

[7] A.E.Badawy, S.M.El-Shazli, A.D.El-Anwar. Ischemic stroke prognosis: clinical and transcranial Doppler study. Zagazig faculty of medicine library,2008. 
[8] R.W.Baumgartner, H.P.Mattle, G Schroth. Assessment of $>50 \%$ and $<50 \%$ intracranial stenosis by transcranial color-coded duplex sonography. Stroke, Vol.30, PP.87-92,1995.

[9] W.Lee. General principles of carotid Doppler ultrasonography. Ultrasonography, Vol.33(1), PP.11$17,2014$.

[10] J.D.Pandian, P.Sudhanb. Stroke Epidemiology and Stroke Care Services in India. J Stroke, Vol.15, PP.128-34,2013.

[11] S.Mainali, M.Wahba, L.Elijovich. Detection of Early Ischemic Changes in Noncontrast CT Head Improved with "Stroke Windows". ISRN neuroscience, Vol.2014, PP.654980,2014.

[12] O.Six. Early brain ischemia signs on CT and MRI - can AI radiology help out? Available at: https://www.quantib.com/blog/early-signs-of-strokeusing-artificial-intelligence-radiology,2018.

[13] K.Lövblad, A.Baird. Computed tomography in acute ischemic stroke. Neuroradiology, Vol. 52, PP.175-187,2010.

[14] J.Gao, M.W.Parsons, H.Kawano. Visibility of CT Early Ischemic Change Is Significantly Associated with Time from Stroke Onset to Baseline Scan beyond the First 3 Hours of Stroke Onset. J.,stroke, Vol.19(3), PP.340-346,2017.

[15] A.Bivard, N.Spratt, C.R.Levi. Acute stroke thrombolysis: time to dispense with the clock and move to tissue-based decision making? Expert Rev Cardiovasc Ther, Vol.9, PP.451-461,2011.

[16] C.Laredo, Y.Zhao, S.Rudilosso. Prognostic Significance of Infarct Size and Location: The Case of Insular Stroke. Scientific reports, Vol.8(1), PP. 9498,2018.

[17] Y.Wang, X.Zhao, L.Liu. Prevalence and outcomes of symptomatic intracranial large artery stenoses and occlusions in China: the Chinese Intracranial Atherosclerosis (CICAS) Study. Stroke, Vol. 45(3), PP. 663 $\pm 9,2014$.

[18] A.D.Boes, S.Prasad, H.Liu. Network localization of neurological symptoms from focal brain lesions. Brain, Vol. 138(10), PP.3061-75,2015.

[19] S.Belagaje. Profiles of the National Institutes of Health Stroke Scale items as a predictor of patient outcome. Stroke, Vol.44, PP.2182-7,2013.

[20] H.S.Nam, H.C.Kim, Y.D.Kim. Long-term mortality in patients with stroke of undetermined etiology. Stroke, Vol.43, PP.2948-2956,2012.

[21] M.Han, H.Nam, Impact of asymmetric middle cerebral artery velocity on functional recovery in patients with transient ischemic attack or acute ischemic stroke. Korean J Clin Lab Sci, Vol.50(2), PP.126-135,2018.

[22] A.Wouters, C.Nysten, V.Thijs, Prediction of Outcome in Patients with Acute Ischemic Stroke Based on Initial Severity and Improvement in the First 24 h. Front. Neurol, Vol. 9, PP.308,2018.
[23] M.Altmann, B.Thommessen, O.M.Rønning. Middle cerebral artery pulsatility index is associated with cognitive impairment in lacunar stroke. J Neuroimaging, Vol.26, PP.431-435,2016.

[24] Y.Kim, H.Lee, S.A.An. The effect of pulsatility index on infarct volume in acute lacunar stroke. Yonsei Med J, Vol.57, PP.950-955,2016.

[25] J.Aoki, L.N.Raber, I.L.Katzan. Postintervention TCD examination may be useful to predict outcome in acute ischemic stroke patients with successful intra-arterial intervention. J.,the Neurological Sciences, Vol. 334(1-2), PP.2629,2013.

[26] T.Asil, I.Uzunca, U.Utku. Monitoring of increased intracranial pressure resulting from cerebral edema with transcranial Doppler sonography in patients with middle cerebral artery infarction. J Ultrasound Med, Vol.22(10), PP.1049-53,2003.

[27] L.Restrepo, A.Y.Razumovsky, W.Ziai. Transcranial Doppler markers of diffusion-perfusion mismatch. J Neuroimaging, Vol.13, PP.34-42,2003.

[28] C.Baracchini, R.Manara, M.Ermani. The quest for early predictors of stroke evolution: can TCD be a guiding light? Stroke, Vol.31, PP.2942-2947,2000.

[29] J-S.Jeng, F.I.Hsieh, H.L.Yeh. Impact of MCA stenosis on the early outcome in acute ischemic stroke patients. PLoS ONE, Vol.12(4), PP. e0175434,2017.

[30] B.M.Famakin, M.I.Chimowitz, M.J.Lynn. Causes and severity of ischemic stroke in patients with symptomatic intracranial arterial stenosis. Stroke, Vol.40(6), PP.1999 $\pm 2003,2009$.

[31] J.Allendoerfer, M.Goertler, G.M.von Reutern. Prognostic relevance of ultra-early Doppler sonography in acute ischaemic stroke: a prospective multicentre study. Lancet Neurol, Vol.5, PP. 835840,2006

[32] E.Stolz, F.Cioli, J.Allendoerfer. Can Early Neurosonology Predict Outcome in Acute Stroke? A Meta-analysis of Prognostic Clinical Effect Sizes Related to the Vascular Status. Stroke, Vol.39, PP.3255-3261,2008.

[33] C.P.Derdeyn, M.I.Chimowitz, M.J.Lynn. Aggressive medical treatment with or without stenting in high-risk patients with intracranial artery stenosis (SAMMPRIS): the final results of a randomised trial. Lancet, Vol.383(9914), PP.333 $\pm 41,2014$.

[34] M.Stelagowski, K.Bogusiak, A.Kasielska. Intracranial occlusions and internal carotid artery stenoses: clinical implications. Annals of vascular surgery, Vol. 24(6), PP.786-93,2010.

[35] M.Kaps, E.Stolz, J.Allendoerfer. Prognostic Value of Transcranial Sonography in Acute Stroke Patients. Eur Neurol, Vol.59(1), PP.9-16,2008. 